\title{
EFFICACY OF FLUIDIZED BED FENTON PROCESS FOR REMOVING COD AND COLOUR FROM SYNTHETIC TEXTILE WASTE WATER
}

\author{
Brijeetha V G', Rana Rahman $\mathbf{M}^{2}$ \\ ${ }^{1} M$ Tech Student, Department of Environmental Engineering, KMCT College of Engineering for Women, Calicut, \\ Kerala, India \\ ${ }^{2}$ Assistant Professor, Department of Environmental Engineering, KMCT College of Engineering for Women, Calicut, \\ Kerala, India
}

\begin{abstract}
In the world, different types of industrial activities are fastly growing day to day and it produced various kinds of wastes and wastewater. Among these fast growing industries most dangerous and needful industry is textile industry. But its effluents are damaged the environment and ecosystem. So its treatment is very essential for maintain the good environment and healthy atmosphere to all creatures in to the earth. The present study mainly focussed on the treatment of synthetic textile wastewater by fluidized bed Fenton process and investigated the efficiency of this Advanced Oxidation process for removing COD and colour. Synthetic textile wastewater prepared by Reactive ultra-red dye. In this study used various parameters such as $\mathrm{pH}$ of solution, $\mathrm{Fe}^{2+}$ concentration and $\mathrm{H}_{2} \mathrm{O}_{2}$ concentration. The fluidization conducted with different carriers like Silicon dioxide and Aluminium Oxide.The comparative study of COD and Dye removal efficiency by two carriers also carried out in this experiment. The study proved that both carriers are effective for achieved the target. But the $\mathrm{Al}_{2} \mathrm{O}_{3}$ experimental result shows that maximum COD removal efficiency of 79\% obtained at $\mathrm{pH}-3, \mathrm{Fe}^{2+}-3 \mathrm{mg} / \mathrm{l}$ and $\mathrm{H}_{2} \mathrm{O}_{2}-200 \mathrm{mg} / \mathrm{l}$ and maximum Dye removal efficiency of $90.1 \%$ attained at $\mathrm{pH}-3, \mathrm{Fe}^{2+}-4 \mathrm{mg} / \mathrm{l}$ and $\mathrm{H}_{2} \mathrm{O}_{2}-200 \mathrm{mg} /$.The $\mathrm{SiO}_{2}$ experimental results shows that maximum $\mathrm{COD}$ removal efficiency of $89 \%$ obtained at $\mathrm{pH}-3, \mathrm{Fe}^{2+}-3 \mathrm{mg} / \mathrm{l}$ and $\mathrm{H}_{2} \mathrm{O}_{2}-200 \mathrm{mg} / \mathrm{l}$ and maximum Dye removal efficiency of $96.8 \%$ attained at $\mathrm{pH}-3, \mathrm{Fe}^{2+}-$ $3 \mathrm{mg} / \mathrm{l}$ and $\mathrm{H}_{2} \mathrm{O}_{2}-200 \mathrm{mg} / \mathrm{l}$. So the present study proved that carrier silicon dioxide is very effective for removing colour and $\mathrm{COD}$ from textile wastewater by Fluidized Bed Fenton process .
\end{abstract}

Keywords: - Textile effluent, Fluidized bed Fenton process, Silicon dioxide, and Aluminum oxide etc...

\section{INTRODUCTION}

Water is an essential and very important for all types of activities on the earth. It is included human activities and industrial or productive activities such as farming different types of industrial activities, tourism, cattle raising etc. Due to the sudden growth of population, the consumption of water is increasing in tremendously. And as a result, there is a large amount of wastewater with different types of degradable and non-degradable materials. The various production processes included in the textile industries are sizing of fibres, scouring, bleaching, washing, mercerization, dyeing and finishing etc. So textile industry consumes more water for its processes.

The mainly used treatment process of dye-contaminated effluents is coagulation, flocculation, precipitation, oxidation, irradiation, incineration, and membrane adsorption. The treatment process of textile wastewater mainly depends on the quality and quantity of textile effluents discharged from the industry. Textile effluents are contained different types of surfactants, dyes, oils, grease, starches, detergents, alkaline and acidic substances etc. All are very harmful to environment and also ecosystem.
Advanced Oxidation Process (AOP) is the best method for treating textile wastewater which is based on the free hydroxyl radicals production $(* \mathrm{OH})$ as a strong oxidant for organic compounds. Advanced Oxidation Process is that makes use of free Hydroxyl radicles in aqueous solution, produced by different chemical, photochemical or electrochemical reactions, to increase the oxidation of organic compounds present in wastewater. Hydroxyl radicals $(\cdot \mathrm{OH})$ are promote radical chain reactions leading to the destruction of aromatic compounds, adsorbable organic halogen (AOX), detergents, pesticides, azo dyes, and phenols [16] . One of the most important processes among AOPs is the $\mathrm{Fe}^{3+} / \mathrm{H}_{2} \mathrm{O}_{2}$ system, the homogeneous Fenton reaction which generates hydroxyl radicals.

This reaction is very easy and does not generate any sludge. So, it has been widely used to degrade pollutants. The $\mathrm{OH}^{*}$ is a powerful oxidant that can rapidly oxidizes organic contaminants into $\mathrm{CO}_{2}$ and $\mathrm{H}_{2} \mathrm{O}$, so it is able to eliminate the pollutants effectively. The most important $\mathrm{AOP}$ is the Fenton's system, the reaction between $\mathrm{H}_{2} \mathrm{O}_{2}$ and $\mathrm{Fe}^{2+}$ in an acidic solution to produce free Hydroxyl radicals.

$$
\mathrm{Fe}^{2+}+\mathrm{H}_{2} \mathrm{O}_{2} \longrightarrow \mathrm{Fe}(\mathrm{OH})^{2+}+\cdot \mathrm{OH}
$$


Hydrogen peroxide can be activated by various methods and it decomposes into hydroxyl radical and hydroxyl ion [1].Hydrogen peroxide is highly affected the decolourisation process because it variously activated to form hydroxyl radicals, which are the strongest existing oxidizing agents [6]. Fenton's reagent (Fe2+ ions and $\mathrm{Fe} 3+$ ions) commonly in to the Fenton's oxidation process used as catalyst for the decomposition of under acidic $\mathrm{pH}$ ranging from 2 to $5[1]$. The main advantage of the Fenton's reagent are readily available, store easily and handle safely [7].This study demonstrates the efficiency of the fluidized bed Fenton reactor in synthetic textile wastewater with different carriers and various parameters. And also compare the efficiency for removing $\mathrm{COD}$ and colour from the textile wastewater by the FBF process with two carriers.

\section{METHODOLOGY}

The different types of methodologies adopted for the removal of COD and colour from synthetic textile wastewater. But in this study, used Fluidised Bed Fenton process for treating the synthetic wastewater .The wastewater is prepared by Ultra Red 3D dye. For the crystallisation process, the fluidised bed filled with carriers, they are Silicon Dioxide $\left(\mathrm{SiO}_{2}\right)$ and Aluminium Oxide $\left(\mathrm{Al}_{2} \mathrm{O}_{3}\right)$

\section{Preparation of Synthetic Wastewater}

The reactive Ultra Red 3D dye was used for preparing the stock solution.100mg Chemifix Ultra red 3D dye powder were mixed with $1000 \mathrm{ml}$ of distilled water for synthetic sample preparation. Then it prepared different concentrations such as 10 to $100 \mathrm{mg} / \mathrm{l}$ for the experiment. After the preparation of synthetic sample ,the characteristics of the wastewater analysed in to the chemical laboratory .The characteristics such as, Chemical Oxygen Demand (COD) , Biological Oxygen Demand (BOD) ,Turbidity,alkalinity, hardness etc.

\section{Experimental Setup}

\section{Fluidised -Bed Fenton Reactor Set up}

The fluidized bed Fenton process is carried out in a fluidized bed reactor. Its dimensions are $1.35 \mathrm{~L}$ height, $5.2 \mathrm{~cm}$ diameter and $133 \mathrm{~cm}$ height. The main parts of the Fluidised Bed reactor are inlet, outlet, and recirculation compartments. Inside of this reactor consists Glass Beads of size $2 \mathrm{~mm}$ are used to support the carrier material. In this study, Quartz $(\mathrm{SiO} 2)$ and Aluminium Dioxide with diameters in the range of $0.5-2 \mathrm{~mm}$, were used as carriers.

\section{Fluidized Bed Fenton Experiment}

In this experiment, the glass beads of $2 \mathrm{~mm}$ diameters are first added to the acrylic tube . It is followed by the addition of $100 \mathrm{~g} / \mathrm{l}$ of $\mathrm{SiO} 2$ carriers or Aluminium Dioxide carrier. About $500 \mathrm{ml}$ of the Reactive dye Sample whose $\mathrm{pH}$ is adjusted by adding sulphuric acidIn this experiment, the glass beads of $2 \mathrm{~mm}$ diameters are first added to the acrylic tube . It is followed by the addition of $100 \mathrm{~g} / \mathrm{l}$ of $\mathrm{SiO} 2$ carriers or Aluminium Dioxide carrier. About 500ml of the Reactive dye Sample whose $\mathrm{pH}$ is adjusted by adding sulphuric acidor Sodium Hydroxide is then introduced into the reactor. The pump was switched on to suspend the carriers and mix the solution. Carriers were fluidized by adjusting the internal circulation at $50 \%$ bed expansion. The reaction began when the $\mathrm{H} 2 \mathrm{O} 2$ and $\mathrm{Fe} 2+$ solution was added.

\section{Result and Discussion}

The chemical oxygen demand (COD) of dye solution was analysed by the standard methods of closed reflux methods of water and wastewater.Thecolour concentration of dye was determined from the Spectrophotometer with calibration graph of different absorbance characteristics.. An UV-Vis Systonics 106 spectrophotometer was used. The maximum absorption measured at the wavelength $(\lambda \max =600 \mathrm{~nm})$ of dye was determined. The absorbance at different known concentration of dye is shown in table below.

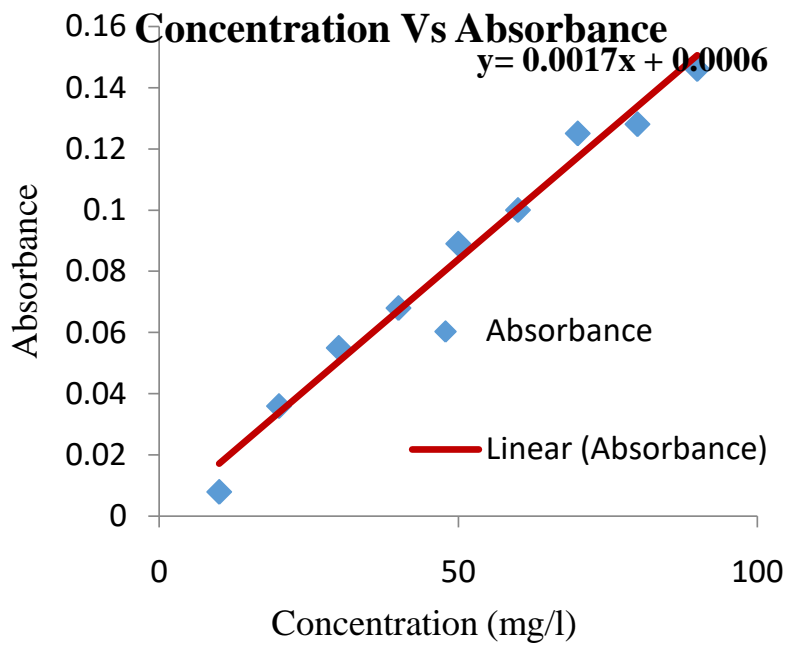

Fig 1: Calibration graph for absorbance

\section{Aluminium Oxide $\left(\mathrm{Al}_{2} \mathrm{O}_{3}\right)$ as a Carrier}

\section{The Effect of pH on Removal of COD and Colour}

The $\mathrm{pH}$ values vary from one sample to other, so $\mathrm{pH}$ values always strongly affected the removal efficiency of the synthetic sample or wastewater. The change in $\mathrm{pH}$ of the solution directly affects the mechanism of oxidation dye, because it involves a variation of the concentration of $\mathrm{Fe}^{2+}$. So the rate of production of $\mathrm{OH}$ radicals responsible for oxidation dyes, will be restricted (NeseErtugey et al, 2012). In this investigation, the $\mathrm{pH}$ values changed as 1 to 8 . As per this study the maximum COD removal and at $\mathrm{pH} 3$ under the conditions of $\mathrm{Fe}^{2+} 2 \mathrm{mg} / \mathrm{l}$ and $\mathrm{H}_{2} \mathrm{O}_{2}$ concentration was $200 \mathrm{mg} / \mathrm{l}$.The removal efficiency was higher in the range of $\mathrm{pH}$ 3-4 after that, the increasing of $\mathrm{pH}$, the removal efficiency was decreased. The reaction rate slowly happened in alkaline medium compared to acidic medium (NeseErtugey et al, 2012).At the low $\mathrm{pH}$,the decrease in 
removal of COD was very speedy process because of the formation of $\mathrm{FeOOH}^{2+}$ and it is competed with iron 2+ to react with hydrogen peroxide(Chia-Chi Su et al ,2011).

Dye removal efficiency also depends on the $\mathrm{pH}$ of the solution. In this study, the maximum dye removal efficiency at acidic $\mathrm{pH} 3$ and the maximum removal is $76 \%$ under the conditions of $\mathrm{Fe}(\mathrm{II}) \quad 2 \mathrm{mg} / \mathrm{l}$ and $\mathrm{H}_{2} \mathrm{O}_{2}$ concentration was $200 \mathrm{mg} / \mathrm{l}$ as per From the maximum dye removal $\mathrm{pH} 3$ to 4,further increasing of the $\mathrm{pH}$ removal efficiency became decreasing. In this investigation the optimum condition was observed at $\mathrm{pH} 3$ for removal of COD and colour.Fig.4.3 showed that the $\mathrm{pH}$ was strongly affected the removal of COD upto 3 then removal efficiency decreased gradually. This proved that acidic range of solution was mostly depends on COD removal.

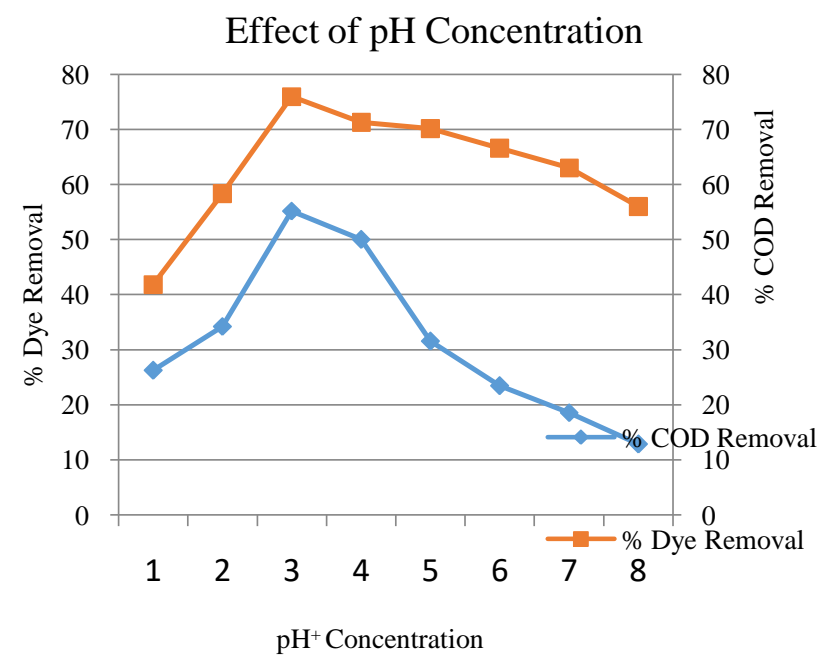

Fig-2: Effect of $\mathrm{pH}$ concentration in COD and Dye removal

\section{The Effect of $\mathrm{Fe}^{2+}$ on Removal of COD and Colour}

In this stage, the dosage of $\mathrm{Fe}^{2+}$ was varied from $1 \mathrm{mg} / \mathrm{l}$ to $8 \mathrm{mg} / \mathrm{l}$ at a constant $\mathrm{H}_{2} \mathrm{O}_{2}$ dosage of $125 \mathrm{mg} / \mathrm{l}$ and $\mathrm{pH}$ of 3 . Under these conditions, the removal efficiency of COD and colour varied from $50 \%$ to $76 \%$ and $56 \%$ to $78 \%$ respectively shown in fig 3 . It is increasing $\mathrm{Fe}^{2+}$ from 2 to $4 \mathrm{mg} / \mathrm{l}$ has a more effective on the efficiency of the degradation of wastewater in fluidised bed fenton process. Increasing the $\mathrm{Fe}^{2+}$ concentration resulted that decreasing the removal efficiency on COD and slightly affect the colour removal efficiency.The overdoses of $\mathrm{Fe}^{2+}$ affect the scavenging effect on $\mathrm{OH}$ radicals. Because in higher dosages of $\mathrm{Fe} 2+, \mathrm{OH}$ radicals may be scavenged by participating in reactions with $\mathrm{Fe} 2+\mathrm{as}$ in reaction 4 (the formation of orange-brown iron precipitate $(\mathrm{Fe}(\mathrm{OH}) 3$ flocs), consequently, the COD removal could decrease .

$$
\mathrm{Fe}^{2+}+\mathrm{HO} * \longrightarrow \mathrm{HO}-+\mathrm{Fe} 3+
$$

Table-2: Optimization of $\mathrm{Fe}^{2+}$ on COD removal and Dye Removal

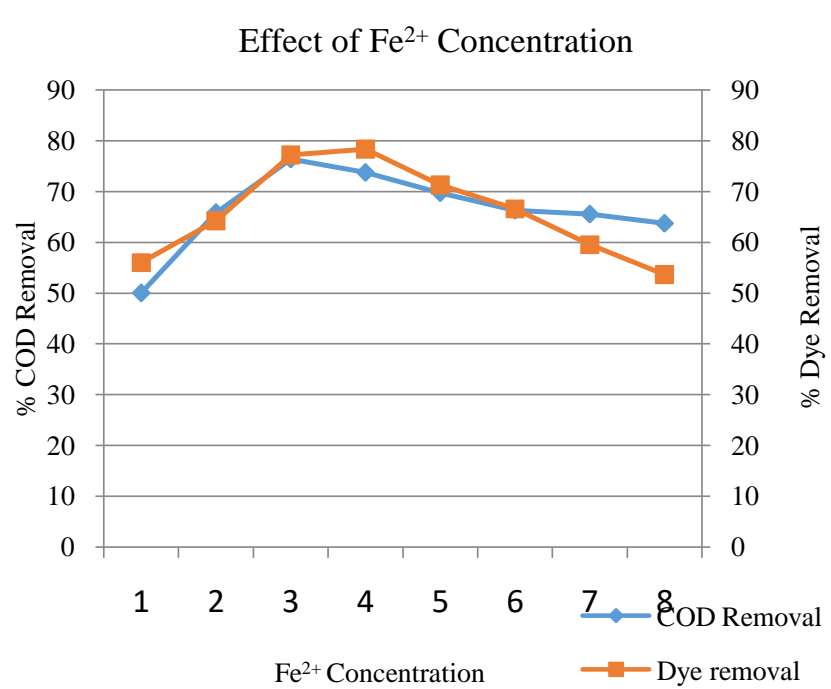

Fig -3: Effect of $\mathrm{Fe}^{2+}$ concentration in COD and Dye removal

\section{The Effect of $\mathrm{H}_{2} \mathrm{O}_{2}$ on Removal of COD and Colour}

$\mathrm{H}_{2} \mathrm{O}_{2}$ concentration is very important factor in Advanced Oxidation Process.It greatly affect the removal of COD and colour from the wastewater by fluidized bed Fenton process. The results from this study shown in fig 4.6. As per the results of degradation of COD and colour, maximum COD removal $79 \%$ at $200 \mathrm{mg} / \mathrm{l}$ of $\mathrm{H}_{2} \mathrm{O}_{2}$ and maximum colour removal $90 \%$ at same conditions ,that is $200 \mathrm{mg} / \mathrm{l} \mathrm{H}_{2} \mathrm{O}_{2}, \mathrm{Fe}$ dosage and $\mathrm{pH}$ was fixed at $3 \mathrm{mg} / \mathrm{l}$ and 3 respectively.

In the optimum concentration of $\mathrm{H}_{2} \mathrm{O}_{2}$, ferrous ions completely oxidized; consequently, the generation of hydroxyl radicals increased. Therefore, $\mathrm{H}_{2} \mathrm{O}_{2}$ dosage of $200 \mathrm{mg} / 1$ with a COD removal efficiency of $79 \%$ and colour removal efficiency of $90 \%$ as the optimum dosage. The excess $\mathrm{H}_{2} \mathrm{O}_{2}$ interferes with the measurement of COD, because the residual amounts of $\mathrm{H}_{2} \mathrm{O}_{2}$ consume $\mathrm{K} 2 \mathrm{Cr} 2 \mathrm{O}$.

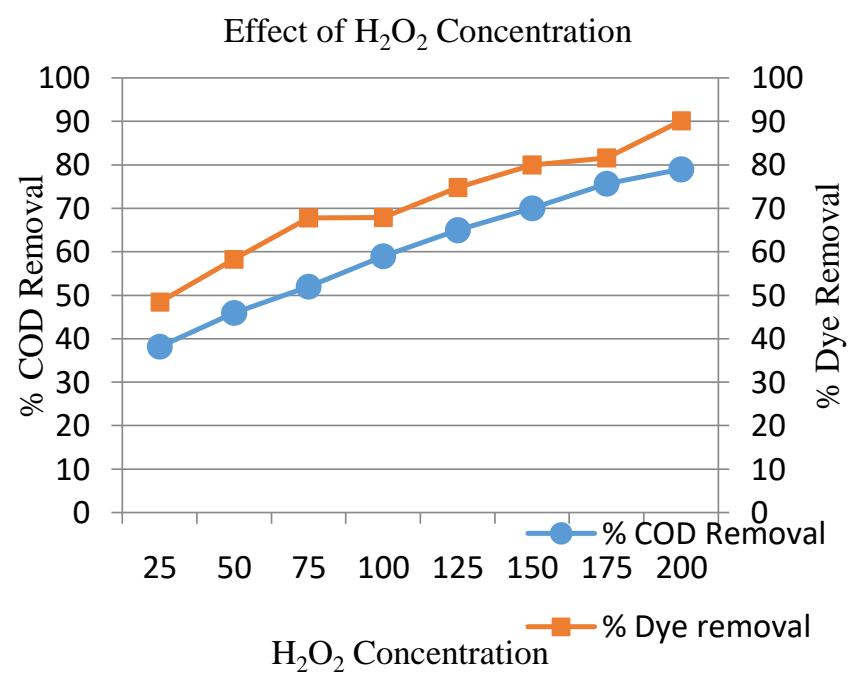

Fig-4: Effect of $\mathrm{H}_{2} \mathrm{O}_{2}$ concentration in COD and Dye removal 


\section{Silicondioxide $\left(\mathrm{Sio}_{2}\right)$ as a Carrier}

\section{The Effect of pH on Removal of COD and Colour}

COD removal efficiency increased with the increasing initial $\mathrm{pH}$ from 3 to 4 , but further increase of $\mathrm{pH}$ reduced the removal efficiency. The same trend was also found in the decolourization (Fig. 4.4). Table 4.4 showed that the removals of COD and colour from the textile wastewater. The highest initial rate of COD obtained at $\mathrm{pH} 3$ and colour also at the conditions fixed at $\mathrm{Fe}=2 \mathrm{mg} / \mathrm{l}$ and $\mathrm{H}_{2} \mathrm{O}_{2}$ $=200 \mathrm{mg} / \mathrm{l}$. The obtained removal efficiency of COD and colour was $58.42 \%$ and $78.35 \%$ respectively (chia chi su et al 2011)

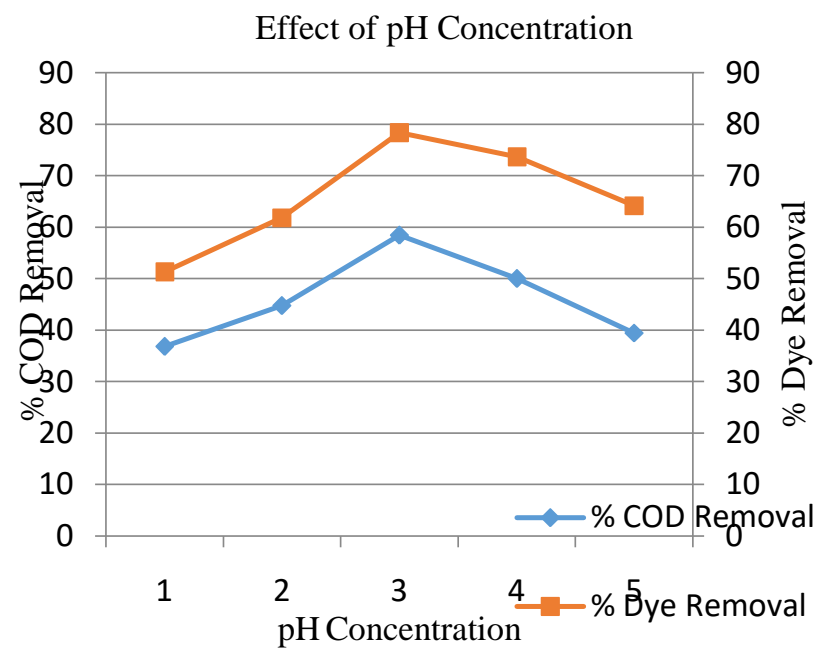

Fig-5: Effect of $\mathrm{pH}$ concentration in COD and Dye removal

\section{The Effect of $\mathrm{Fe}^{2+}$ on Removal of COD and Colour}

The Ferrous ions catalyse the rapid decomposition of $\mathrm{H}_{2} \mathrm{O}_{2}$ to form hydroxyl radicals; The maximum $\mathrm{COD}$ removal efficiency obtained at the Fe ions concentration at $3 \mathrm{mg} / \mathrm{l}$ and constant parameters $\mathrm{pH}=3, \mathrm{H}_{2} \mathrm{O}_{2}=200 \mathrm{mg} / \mathrm{l}$.

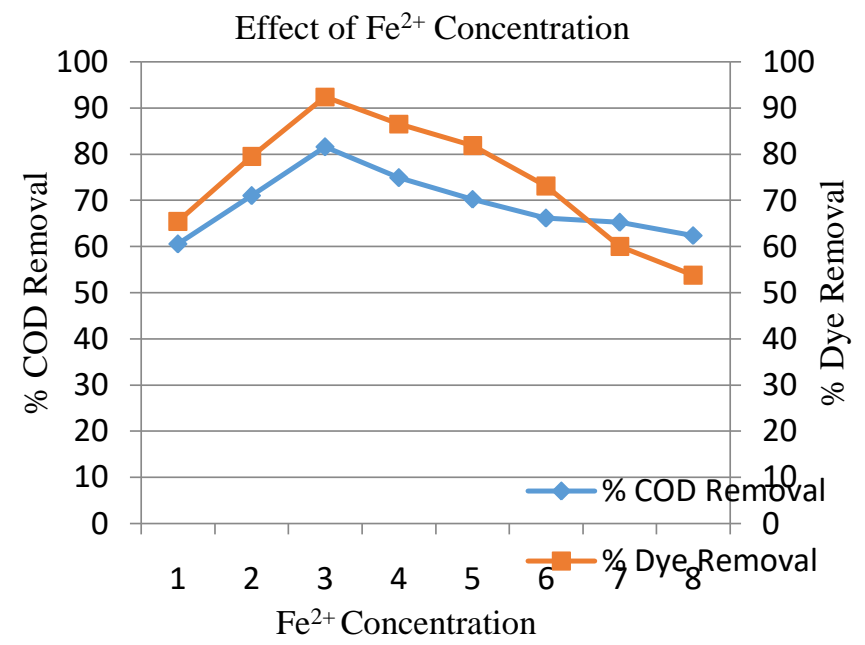

Fig -6: Effect of $\mathrm{Fe}^{2+}$ concentration in COD and Dye removal

\section{The Effect of $\mathrm{H}_{2} \mathrm{O}_{2}$ on Removal of COD and Colour}

The Hydrogen peroxide greatly affects the colour and COD removal from the textile wastewater with the use of carrier Silicon Dioxide in Fluidized Bed Fenton process. In this study ,Hydrogen peroxide dosage as $25,50,75,100,125,150,175 \& 200 \mathrm{mg} / 1$.Maximum removal achieved in $200 \mathrm{mg} / \mathrm{l}$ at the conditions of $\mathrm{pH} 3$ in both COD removal and Dye removal. But the ferrous ions concentrations were changed in to the maximum removal efficiency of COD and Colour. The maximum COD removal at $\mathrm{Fe}^{2+}$ concentration on $3 \mathrm{mg} / \mathrm{l}$ and $4 \mathrm{mg} / \mathrm{l}$ used for the maximum removal of colour.The maximum removal of COD and Colour under these conditions was $89 \%$ and $96.8 \%$ respectively.

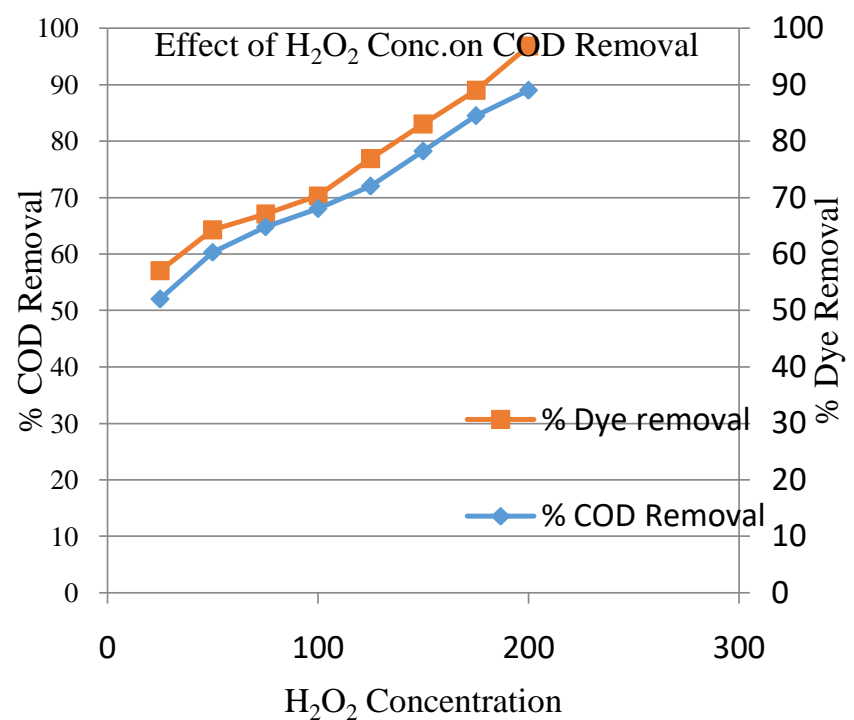

Fig-7: Effect of $\mathrm{H}_{2} \mathrm{O}_{2}$ concentration in COD and Dye removal

\section{Comparative Study of Cod and Dye Removal By} Two Carriers

The comparative study conducted for showing the efficiency of different carriers such as Silicon Dioxide and Aluminium Oxide in the treatment of textile wastewater by Fluidized Bed Fenton Process.

Different variables or parameters were analysed, they are $\mathrm{pH}$ of the solution, ferrous ions dosage and Hydrogen peroxide concentration. After the study, it proved that Silicon dioxide was effective carrier for treating the textile waste water rather than aluminium oxide because silicon dioxide removal efficiency was very higher compared to aluminium oxide with same concentration of $\mathrm{pH}$ and $\mathrm{H}_{2} \mathrm{O}_{2}$.

When aluminium oxide was used as carrier the removal efficiency of COD obtained at maximum as $55.2 \%$ under the conditions of $\mathrm{pH} 3$ and $58.42 \%$ removal efficiency shown by the use of Silicon Dioxide carrier at same condition of $\mathrm{pH} 3$. 
Comparative study on \% COD removal with two Carriers

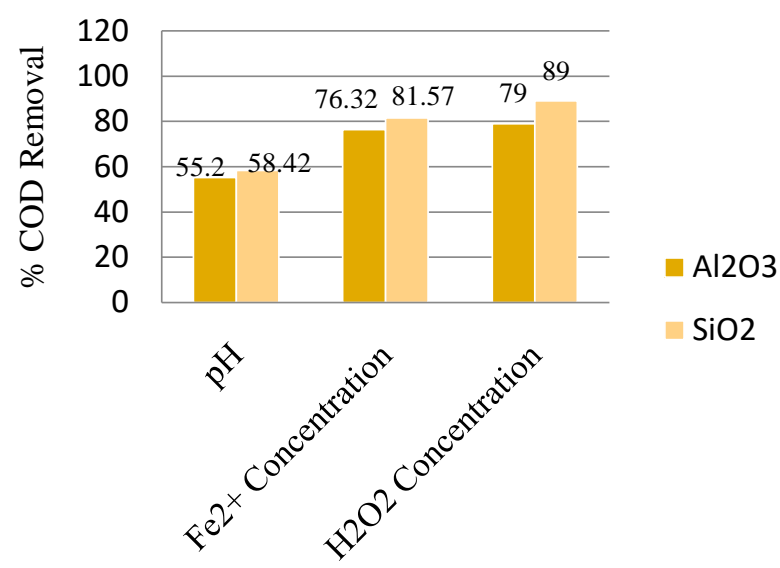

Chart-1: Comparative study on COD removal with two carriers

As per chart-1., the COD removal efficiency of $\mathrm{Al}_{2} \mathrm{O}_{3}$ and $\mathrm{SiO}_{2}$ were $76.32 \%$ and $81.57 \%$ respectively under the conditions of ferrous ions dosage as $3 \mathrm{mg} / \mathrm{l}$ in $\mathrm{Al}_{2} \mathrm{O}_{3}$ carrier and $4 \mathrm{mg} / \mathrm{l}$ in $\mathrm{SiO}_{2}$ carrier. And Hydrogen peroxide at $200 \mathrm{mg} / \mathrm{l}$, the COD removal efficiency became $79 \%$ and $89 \%$ in to the use of $\mathrm{Al}_{2} \mathrm{O}_{3}$ and $\mathrm{SiO}_{2}$.

\section{Comparative Study on \% Dye Removal with Two Carriers}

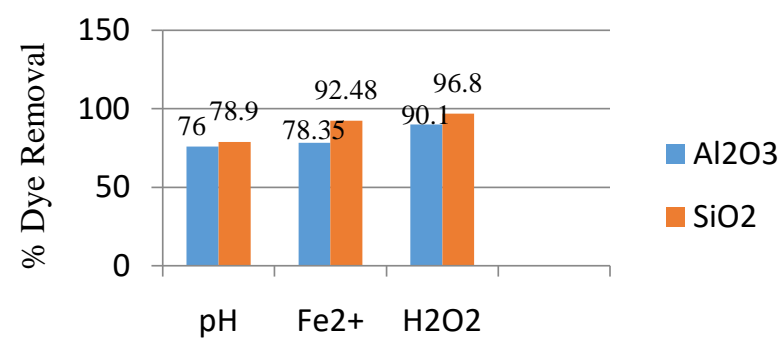

Chart-1: Comparative study on Dye removal with two carriers

Chart-2 shows that, both carriers were obtained maximum dye removal at $\mathrm{pH} 3$ and dye removal efficiency was $76 \%$ and $78.4 \%$ in $\mathrm{Al}_{2} \mathrm{O}_{3}$ and $\mathrm{SiO}_{2}$ respectively. But in the case of ferrous ions with $\mathrm{SiO}_{2}$ and $\mathrm{Al}_{2} \mathrm{O}_{3}$ carriers were maximum at $4 \mathrm{mg} / \mathrm{l}$ of $\mathrm{Fe}^{+}$of removal efficiency was $80.3 \%$ and $92.8 \%$ respectively. Same as the maximum removal efficiency was obtained at $200 \mathrm{mg} / \mathrm{l}$ of $\mathrm{H}_{2} \mathrm{O}_{2}$ and its dye removal efficiency was $90 \%$ and $96.8 \%$ with the use of $\mathrm{Al}_{2} \mathrm{O}_{3}$ and $\mathrm{SiO}_{2}$ respectively.

\section{CONCLUSION}

This study investigated the decolourization and cod removal from the synthetic textile wastewater by the use of fluidized bed Fenton process. This study proved that all type of degradation efficiency depended upon the variables like that
$\mathrm{pH}$, concentration of $\mathrm{H}_{2} \mathrm{O}_{2}$ and $\mathrm{Fe}^{2+}$.COD analyser and spectrophotometer were used for monitoring the COD and colour.

In this study was analysed effectiveness of different parameters on degradation efficiency and it was also conducted comparative study of maximum removal efficiency by the use of different carriers such as Silicon Dioxide and Aluminium oxide.

The maximum COD removal of $79 \%$ at $\mathrm{pH}-3, \mathrm{Fe}^{2+}-3 \mathrm{mg} / \mathrm{l}$ and $\mathrm{H}_{2} \mathrm{O}_{2}-200 \mathrm{mg} / \mathrm{l}$ and maximum dye removal of $90.1 \%$ under the optimum conditions such as $\mathrm{pH}-3, \mathrm{Fe}^{2+}-4 \mathrm{mg} / \mathrm{l}$ and $\mathrm{H}_{2} \mathrm{O}_{2}-200 \mathrm{mg} / \mathrm{l}$ by the use of aluminium oxide as the carrier. But in the case of silicon dioxide ,the maximum COD removal efficiency of $89 \%$ and dye removal efficiency of $96.8 \%$.The optimum conditions of COD removal efficiency was $\mathrm{pH}-3, \mathrm{Fe}^{2+}-3 \mathrm{mg} / \mathrm{l}$ and $\mathrm{H}_{2} \mathrm{O}_{2}-200 \mathrm{mg} / \mathrm{l}$ and same optimum conditions of dye removal efficiency also.

So it can be concluded that, Silicon dioxide is the best carrier for removing colour and COD from the textile wastewater by Fluidized bed Fenton process. Silicon dioxide can reacted with Fenton's reagent in faster and effective manner and it affected crystallization during the fluidization time.

\section{REFERENCES}

[1] RutviJogani, Hardik Bhervia1, Shivam Kapoor and Dr.Anantha Singh (2017) Optimization of different variables used in Fenton reagent process for removal of direct red 80 dye, Int'l Journal of Advances in Agricultural \& Environmental Engg. (ISSN 23491523 EISSN 2349-1531)

[2] Huma Hayat, Qaisar Mahmood , Arshid Pervez, Zulfiqar Ahmad Bhatti, Shams Ali Baig (2015) Comparative decolorization of dyes in textile wastewater using biological and chemical treatment, journal of separation and purification technology 154.149-153

[3] W.Miled,A Haj Said and S.Roudesli (2010) Decolourization of high polluted textile wastewater by indirect electrochemical oxidation process,Journal of textile and apparel ,technology and management vol. 6 issue -3

[4] Abbas

Rezaee,Mohammadtaghighanejan,SayyedJamoldinHa shemian,GholamrezaMoussavi,AliKhavanin and ghaderghanizadeh(2008) Decolourization of reactive blue 19 dye from textile wastewater by the $\mathrm{UV} / \mathrm{H}_{2} \mathrm{O}_{2}$ process,Journal of applied sciences $8(6)$ 1108-1112

[5] Oscar Primo, Mar'ia J. Rivero, Inmaculada Ortiz (2007) Photo-Fenton process as an efficient alternative to the treatment of landfill leachates,Journal of hazardous materials 153,834 842 
[6] Sangyong Kim, Chulhwan Park, Tak-Hyun Kim,Jjnwon Lee, And Seung-Wook Kim(2003) COD reduction and decolorization of textile effluent using a combined process, journal of bioscience and bioengineering 102-105.

[7] K.Murugesan and P.Kalaichelvan (2003),Synthetic dye decolourization by white rot fungi,Indian journal of experimental biology 1076-1087

[8] S. Sena, G.N. Demirerb (2003) Anaerobic treatment of real textile wastewater with a fluidized bed reactor ,Journal of water research 1868-1878

[9] J.M. Peralta-Hernández, Carlos A. Martínez- Huitle, Jorge L. Guzmán-Mar1 and A. HernándezRamírez(2009)Recent Advances in the Application Of Electro-Fenton And Photoelectro-Fenton Process for Removal of Synthetic Dyes In Wastewater Treatment, J. Environ. Eng. Manage, 19(5), 257-265

[10] Tak-Hyun Kima,b, Chulhwan Parka, JinwonLeec, Eung-Bai Shinb,Sangyong Kim (2002) Pilot scale treatment of textile wastewater by combined process (fluidized biofilm process-chemical coagulationelectrochemical oxidation), Journal of water research 3979-3988

[11] Sruthi K., Sosamony K. J.(2014) Treatment of textile wastewater using electrofentonprocess,International journal of civil engineering and technology 248-255

[12] FatemehAnvari ,Monire Kheirkhah1, Reza Amraei (2014) Treatment of synthetic textile wastewater by combination of coagulation/flocculation process and electron beam irradiation, journal of community health research 3(1):31-38.

[13] Chia-Chi Su , MassakulPukdee-Asa , ChavalitRatanatamskul , Ming-Chun Lu (2011) Effect of operating parameters on the decolorization and oxidation of textile wastewater by the fluidizedbed Fenton process, journal of separation and purification technology $83,100-105$

[14] Maria Cristina Collivignarelli, Roberta Pedrazzani , Sabrina Sorlini, Alessandro Abbà , and Giorgio Bertanza (2017) H2O2 based oxidation processes for the treatment of real high strengthaqueouswastes,journal of sustainability

[15] Prashant K. Lalwani *, Malu D. Devadasan (2013) Reduction of cod and bod by oxidation: a cetp case study, International Journal of Engineering Research and Applications 108-112

[16] NeseErtugey,FilisNuranAcar (2013) Removal of cod and colour from direct blue 71 azo dye wastewater by fenton's oxidation: kinetic Study, Arabian Journal of chemistry10, S1158-S1163

[17] Muhammad Saqib Nawaz, Muhammad Ahsan(2014), Comparison of physico-chemical, advanced oxidation and biological techniques for the textile wastewater treatment, Alexandria Engineering Journal, 53, 717722

[18] MuqingQiu,

JianxinShouYanni Lu(2014),Degradation of organic compounds by fluidized bed fenton process, Journal of Chemical and Pharmaceutical Research, 6(7),2033-2038
[19] Chia-Chi Su, Chia-Min Chen, JinAnotai , Ming-Chun $\mathrm{Lu}(2013)$, Removal of monoethanolamine and phosphate from thin-film transistor liquid crystal display (TFT-LCD) wastewater by the fluidized-bed Fenton process, Chemical Engineering Journal,222 ,128-135

[20] NeseErtugey,FilisNuranAcar(2013), Removal of COD and Colour from Direct Blue 71 Azo Dye wastewater by Fenton's Oxidation:Kinetic Study, Arabian Journal of chemistry

\section{BIOGRAPHIES}

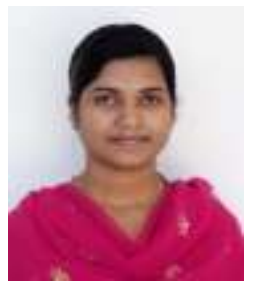

Brijeetha V G, M.tech student in environmental engineering at KMCT college of Engineering for women Calicut,Kerala

RanaRahman.M, Faculty of Civil engineering Department at KMCT college of Engineering for women Calicut,Kerala 